\title{
First-principles investigation of hydrous post-perovskite
}

\author{
Joshua P Townsend ${ }^{\mathrm{a}, *}$, Jun Tsuchiya ${ }^{\mathrm{b}}$, Craig R Bina ${ }^{\mathrm{a}}$, Steven D Jacobsen ${ }^{\mathrm{a}}$ \\ ${ }^{a}$ Department of Earth and Planetary Sciences, Northwestern University, Evanston, IL 60208 \\ ${ }^{b}$ Geodynamics Research Center, Ehime University, Matsuyama, Ehime 790, Japan
}

\section{Abstract}

A stable, hydrogen-defect structure of post-perovskite (hy-ppv, $\mathrm{Mg}_{1-x} \mathrm{SiH}_{2 x} \mathrm{O}_{3}$ ) has been determined by first-principles calculations of the vibrational and elastic properties up to $150 \mathrm{GPa}$. Among three potential hy-ppv structures analyzed, one was found to be stable at pressures relevant to the lower-mantle $\mathrm{D}^{\prime \prime}$ region. Hydrogen has a pronounced effect on the elastic properties of post-perovskite due to magnesium defects associated with hydration, including a reduction of the zero-pressure bulk $\left(K_{0}\right)$ and shear $\left(G_{0}\right)$ moduli by $5 \%$ and $8 \%$, respectively, for a structure containing $\sim 1 \mathrm{wt} . \% \mathrm{H}_{2} \mathrm{O}$. However, with increasing pressure the moduli of hy-ppv increase significantly relative to ppv, resulting in a structure that is only $1 \%$ slower in bulk compressional velocity and $2.5 \%$ slower in shear-wave velocity than ppv at $120 \mathrm{GPa}$. In contrast, the reduction of certain anisotropic elastic constants $\left(\mathrm{C}_{i j}\right)$ in hy-ppv increases with pressure (notably, $\mathrm{C}_{55}$, $\mathrm{C}_{66}$, and $\mathrm{C}_{23}$ ), indicating that hydration generally increases elastic anisotropy in hy-ppv at $\mathrm{D}^{\prime \prime}$ pressures. Calculated infrared absorption spectra show two O-H stretching bands at $\sim 3500 \mathrm{~cm}^{-1}$ that shift with pressure to lower wavenumber by about $2 \mathrm{~cm}^{-1}$ per GPa. At $120 \mathrm{GPa}$ the hydrogen bonds in hy-ppv are still asymmetric. The stability of a hy-ppv structure containing 1-2 wt. $\% \mathrm{H}_{2} \mathrm{O}$ at $\mathrm{D}^{\prime \prime}$ pressures implies that post-perovskite may be a host for recycled or primordial hydrogen near the Earth's core-mantle boundary.

6 Keywords: Hydrogen, Post-perovskite, Lower mantle, Elasticity

*Corresponding Author

Email address: joshua@earth.northwestern.edu (Joshua P Townsend)

Preprint submitted to Physics of the Earth and Planetary Interiors

January 20, 2015 


\section{Introduction}

8 Seismic investigations of the lowermost several hundred kilometers of the mantle (called

9 the $\mathrm{D}^{\prime \prime}$ region) have revealed a heterogeneous region with large-scale structures including large

10 low-shear-velocity provinces (LLSVPs) and ultralow-velocity zones (ULVZs) overlying the core

11 (Garnero and McNamara, 2008). The bridgmanite (brg) to post-perovskite (ppv) phase transi-

12 tion of $\mathrm{MgSiO}_{3}$ has been invoked to explain some of the features within the $\mathrm{D}^{\prime \prime}$ region $(\mathrm{Mu}-$

13 rakami et al., 2004; Tsuchiya et al., 2004; Oganov and Ono, 2004; Wookey et al., 2005; Nowacki

14 et al., 2010). The composition and mineralogy of $\mathrm{D}^{\prime \prime}$ remains unresolved due to uncertainties

15 in core-mantle boundary (CMB) temperature (Nomura et al., 2014), spatial heterogeneity of $\mathrm{D}^{\prime \prime}$

${ }_{16}$ material (e.g. slab graveyards) (Garnero and McNamara, 2008), and the effect of major element

substitution on physical properties of the brg/ppv phase boundary for candidate lower mantle compositions (Grocholski et al., 2012).

Previous studies have investigated the effect of major-element substitution on the bridgmanite

to post-perovskite phase transition and on physical properties of post-perovskite (Murakami and Hirose, 2005; Mao et al., 2006; Grocholski et al., 2012). In Al-free systems, increasing $\mathrm{Fe}^{2+}$ decreases the pressure of the phase boundary, whereas increasing $\mathrm{Fe}^{3+}$ and Al-content suppresses the phase boundary to higher pressures (greater depths) (Grocholski et al., 2012). The brg to ppv transition should occur above the CMB in harzburgite and MORB but potentially below the CMB conditions in pyrolite (Grocholski et al., 2012). However, the influence of hydrogen on ppv structure and physical properties has not been determined.

The bulk $\mathrm{H}_{2} \mathrm{O}$ content of the mantle is among the least well constrained compositional parameters of the Earth, with estimates varying by orders of magnitude due to uncertainty in the bulk mantle and core hydrogen content (e.g. Williams and Hemley, 2001). The water storage capacity of the uppermost mantle varies with depth, but in the peridotite system olivine and pyroxene can contain about $0.1 \mathrm{wt} \% \mathrm{H}_{2} \mathrm{O}$ at $400 \mathrm{~km}$ depth (Tenner et al., 2012; Ferot and Bolfan-Casanova, 2012). The transition zone water storage capacity is likely much higher because wadsleyite and ringwoodite can incorporate 1-2 wt.\% $\mathrm{H}_{2} \mathrm{O}$ into their structures (Bolfan-Casanova et al., 2000; Inoue et al., 2010; Kohlstedt et al., 1996). The recent discovery of a hydrous ringwoodite inclusion in diamond containing $\sim 1.5 \mathrm{wt} . \% \mathrm{H}_{2} \mathrm{O}$ suggests the transition zone may be very hydrous, at least locally (Pearson et al., 2014). The $\mathrm{H}_{2} \mathrm{O}$ storage capacity of the lower mantle remains highly uncertain due to conflicting estimates of $\mathrm{H}_{2} \mathrm{O}$ storage capacity of bridgmanite, which range from 
about 0.001 wt.\% (Bolfan-Casanova et al., 2003) to 0.4 wt.\% (Murakami et al., 2002) and values in between (Litasov et al., 2003). A recent computational investigation by Hernandez et al. (2013) investigated the hydrogen partition coefficient between ringwoodite, ferropericlase, and bridgmanite and estimated that bridgmanite may contain up to $1000 \mathrm{ppm}(0.1 \mathrm{wt} \%)$ water. Contrast in the $\mathrm{H}_{2} \mathrm{O}$ storage capacity between ringwoodite and bridgmanite may lead to dehydration melting below the $660 \mathrm{~km}$ discontinuity and provide evidence for regional scale hydration of the transition zone (Schmandt et al., 2014).

In contrast to bridgmanite, the post-perovskite structure is potentially more accommodating of hydrogen because both oxygen sites of the structure are slightly under-bonded. Magnesium is coordinated to eight oxygens with interatomic distances less than $2 \AA$ and to two oxygens with distances slightly longer than $2 \AA$ (Zhang et al., 2013). If the two longer oxygens are excluded from the Pauling bond strength sum, both $\mathrm{O} 1$ and $\mathrm{O} 2$ have the potential to protonate with charge balance achieved by an Mg-site vacancy. To test the idea that ppv may store seismically detectable amounts of hydrogen at $\mathrm{D}^{\prime \prime}$ pressures, we have investigated several potential hydrous post-perovskite structures using density functional theory (DFT). We describe the most favorable hy-ppv structure and calculate its elastic and vibrational properties under static conditions in order to determine its mechanical stability, single-crystal and bulk-elastic wave velocities, and infrared absorption spectra.

\section{Methods}

Post-perovskite is orthorhombic with space group Cmcm (Murakami et al., 2004; Tsuchiya et al., 2004; Oganov and Ono, 2004). The structure contains alternating layers of corner-sharing $\mathrm{SiO}_{6}$ octahedra and $\mathrm{Mg}$ polyhedra in eight coordination to oxygen (Murakami et al., 2004; Zhang et al., 2013). DFT calculations were carried out using the PWSCF code, part of the Quantum ESPRESSO package using the Perdew-Ernzerhof-Burke generalized gradient approximation (Hohenberg, 1964; Kohn and Sham, 1965; Perdew et al., 1996; Giannozzi et al., 2009). Wavefunctions were expanded with plane waves using an energy cutoff of 100 Ry. Norm-conserving pseudopotentials were used to describe H, O, and Si (Troullier and Martins, 1991). The Mg pseudopotential was generated by the method of U. von Barth and R. Car and has been used in previous investigations of hydrogen in silicates (Karki and Wentzcovitch, 2000; Tsuchiya et al., 2004; Tsuchiya and Tsuchiya, 2009). A supercell consisting of 4x1x1 ppv unit cells (80-82 
atoms) was used for all calculations. The irreducible Brillouin zone was sampled on a 2x2x2 Monkhorst-Pack mesh (Monkhorst and Pack, 1976). Both plane-wave cutoff energy and mesh size were tested for adequate total energy convergence. Unit-cell parameters and atomic coordinates were simultaneously relaxed at $0 \mathrm{~K}$ with a force convergence criterion of $10^{-5} \mathrm{Ry} / \mathrm{Bohr}$.

Because there are no experimental data available for hydrous ppv, $\mathrm{H}$ defects were created by introducing $\mathrm{Mg}$-site vacancies, $\mathrm{Mg}_{1-x} \mathrm{SiH}_{2 x} \mathrm{O}_{3}$, as similar vacancy structures have been reported in other high-pressure silicates such as wadsleyite and ringwoodite (Tsuchiya and Tsuchiya, 2009; Kudoh and Inoue, 1999; Li et al., 2009; Ganskow et al., 2010; Verma and Karki, 2009). Coupled substitutions of $\mathrm{Fe}^{3+}$ or $\mathrm{Al}^{3+}$ and $\mathrm{H}^{+}$for $\mathrm{Si}^{4+}$ may also be important in the ppv phase, but in this study we first consider only charge-balanced vacancy substitutions in which one magnesium atom from the ppv 4x1x1 supercell was replaced with two hydrogen atoms $\left(\mathrm{Mg}_{0.938} \mathrm{SiH}_{0.125} \mathrm{O}_{3}\right)$, corresponding to a concentration of approximately 1.14 wt. $\% \mathrm{H}_{2} \mathrm{O}$. We also created a second structure in the same scheme as above, but with 2 magnesium vacancies and 4 hydrogen $\left(\mathrm{Mg}_{0.875} \mathrm{SiH}_{0.250} \mathrm{O}_{3}\right)$ corresponding to $2.31 \mathrm{wt} \% \mathrm{H}_{2} \mathrm{O}$. In the more hydrous model the magnesium vacancies were created such that the vacancies were far apart ( $>7 \AA$ at $0 \mathrm{GPa}$ ) to minimize interactions between vacancies. The 9 single-crystal elastic components were obtained from calculations of total energy and stress for incrementally strained orthorhombic super-cells (Karki et al., 2001). The largest strain was 0.01 and was checked to ensure a linear response. The infrared spectrum of hy-ppv was calculated for several pressures at the $\Gamma$-point under $0 \mathrm{~K}$ conditions via density functional perturbation theory under the linear-response theory of Baroni et al. (2001) in which the dynamical matrix along with dielectric quantities such as the Born effective charge tensor are evaluated at the $\Gamma$-point. The scheme outlined above is similar to previous abinitio calculations of IR spectra for hydrous silicates (Karki and Wentzcovitch, 2000; Blanchard et al., 2009; Verma and Karki, 2009; Brodholt and Refson, 2000; Umemoto et al., 2011).

\section{Results and Discussion}

Three potential OH-defect structures of post-perovskite were studied by positioning hydrogen in a magnesium vacancy of the ppv supercell using the electron localization function (Gibbs et al., 2003) to identify initial H positions. The first model (hy-ppv1) features one O1-H group and one $\mathrm{O} 2-\mathrm{H}$ group, the second (hy-ppv2) features two approximately symmetric $\mathrm{O} 2-\mathrm{H}$ groups, and the third model (hy-ppv3) features two asymmetric O2-H groups. After calculation of 

122 for a simple $\mathrm{Mg}-2 \mathrm{H}$ substitution.

phonons and enthalpy under static conditions for all structures, the stable H-defect structure is hy-ppv3 (hereafter hy-ppv), which features two distinct asymmetric hydrogen bonds as $\mathrm{O} 2-\mathrm{H}$ groups oriented in a plane normal to the a-axis. The hy-ppv1 structure was rejected due to unstable phonon modes, and hy-ppv2, although stable, has a higher enthalpy than hy-ppv3 at $0 \mathrm{~K}$ at all pressures considered in this study (by about $0.10 \mathrm{eV}$ per formula unit).

The stable structure of hy-ppv at $120 \mathrm{GPa}$ is illustrated in Figure 1. At $0 \mathrm{GPa}$, the O-H bond distance is $0.98 \AA$, with a hydrogen bond geometry of $d(\mathrm{H} . . \mathrm{O})=2.17 \AA, d(\mathrm{O} . . \mathrm{O})=2.73 \AA$, and hydrogen bond angle $115^{\circ}$. For comparison, the hydrogen-bond geometry in hydrous bridgmanite (Hernandez et al., 2013) is $d(\mathrm{O}-\mathrm{H})=1.1 \AA, d(\mathrm{H} . . . \mathrm{O})=1.65 \AA$, with a hydrogen-bond angle of about $150^{\circ}$. Thus, the hydrogen bond in hy-ppv is considerably more non-linear than in hy-brg. In hy-ppv, the $\mathrm{O}-\mathrm{H}$ bond distance increases slightly with pressure as the hydrogen bond distance $d(\mathrm{O} \ldots \mathrm{O})$ shortens, consistent with general trends among hydrogen bonds in minerals (Libowitzky, 1999). Lattice parameters, energies, and hydrogen-bond geometry of hy-ppv at 0 and $120 \mathrm{GPa}$ are listed in Table 1. Fractional coordinates of all the atom positions in all structures and all pressures are provided in the supplementary materials.

The effect of hydrogen on the elastic tensor of ppv is shown in Figure 2. Generally $\mathrm{C}_{44}, \mathrm{C}_{55}$, $\mathrm{C}_{66}$, and $\mathrm{C}_{23}$ are most sensitive to hydration, with the most sensitive component $\mathrm{C}_{66}$, reduced by $20 \%$ at $120 \mathrm{GPa}$ for the 2.31 wt. $\% \mathrm{H}_{2} \mathrm{O}$ hy-ppv structure. We used the Born stability criteria to determine the mechanical stability of hy-ppv compared to ppv (Born and Huang, 1954). In the case of orthorhombic symmetry, these criteria reduce to the following:

$$
B_{1, i i}=C_{i i}>0(i=1,2,3, \ldots, 6)
$$

$$
B_{2, i j}=\operatorname{det}\left|\begin{array}{ll}
C_{i i} & C_{i j} \\
C_{j i} & C_{j j}
\end{array}\right|>0(i, j=\{1,2,3\}, i \neq j)
$$

$$
B_{3}=\operatorname{det}\left|\begin{array}{lll}
C_{11} & C_{12} & C_{13} \\
C_{21} & C_{22} & C_{23} \\
C_{31} & C_{32} & C_{33}
\end{array}\right|>0
$$

The Born stability criteria calculated for pure ppv and hy-ppv are shown in Figure 3 and indicate that hydrogen does not destabilize the post-perovskite lattice over lower mantle pressures 
Bulk elastic properties for ppv and hy-ppv were calculated from the single crystal elastic tensors using the Voigt-Reuss-Hill averaging scheme and are shown in Figure 4 (Hill, 1952). The Hill averaged elastic wave velocities decrease with hydration, as expected, but the bulk sound velocity $\left(V_{\Phi}\right)$ is remarkably insensitive to the presence of hydrogen. At $120 \mathrm{GPa} V_{\Phi}$ is reduced by $8 \mathrm{~m} / \mathrm{s}$ per wt. $\% \mathrm{H}_{2} \mathrm{O}(<0.1 \%$ decrease $)$. In contrast to the bulk sound velocity, both the Hill averaged $\mathrm{P}$-wave $\left(V_{P}\right)$ and $\mathrm{S}$-wave $\left(V_{S}\right)$ velocities decrease by approximately $68 \mathrm{~m} / \mathrm{s}$ per wt. $\% \mathrm{H}_{2} \mathrm{O}(0.5 \%$ decrease $)$ and $85 \mathrm{~m} / \mathrm{s}$ per wt. $\% \mathrm{H}_{2} \mathrm{O}(1.1 \%$ decrease $)$, respectively, at $120 \mathrm{GPa}$. Of particular note is that at $120 \mathrm{GPa}$ the S-wave velocity of hy-ppv is slower than ppv and brg (for the $2.31 \mathrm{wt} . \% \mathrm{H}_{2} \mathrm{O}$ model), implying that a very hydrous hy-ppv, if present in $\mathrm{D}^{\prime \prime}$, may be difficult to distinguish from bridgmanite using bulk sound velocity and/or shear-wave profiles alone.

The Hill averages of the bulk and shear moduli of ppv decrease linearly with water content, as shown in Figure 5. At $0 \mathrm{GPa}$, the bulk modulus of ppv decreases by $9.6 \mathrm{GPa}$ per wt. $\% \mathrm{H}_{2} \mathrm{O}$, corresponding to $4.5 \%$ reduction per wt. $\% \mathrm{H}_{2} \mathrm{O}$ relative to the dry ppv $K_{0}=214 \mathrm{GPa}$. The effect of water on the bulk modulus is significantly less at $120 \mathrm{GPa}$, with about $7.4 \mathrm{GPa}$ reduction per wt. $\% \mathrm{H}_{2} \mathrm{O}$, corresponding to only about $1 \%$ reduction in $K$ per wt. $\% \mathrm{H}_{2} \mathrm{O}$ relative to the dry $K_{120}=677 \mathrm{GPa}$. In contrast, the shear modulus decreases by $9.3 \mathrm{GPa}$ per wt. $\% \mathrm{H}_{2} \mathrm{O}$ at $0 \mathrm{GPa}$, corresponding to a $8.1 \%$ reduction per wt. $\% \mathrm{H}_{2} \mathrm{O}$ relative to the dry $G_{0}=114 \mathrm{GPa}$. At $120 \mathrm{GPa}$, the shear modulus decreases by $10.3 \mathrm{GPa}$ per wt. $\% \mathrm{H}_{2} \mathrm{O}$, corresponding to about $3.1 \%$ reduction per wt. $\% \mathrm{H}_{2} \mathrm{O}$ relative to the dry $G_{120}=336 \mathrm{GPa}$. For comparison, the bulk modulus $K_{0}=203$ GPa for $\mathrm{Mg}$ hy-ppv containing $\sim 1 \mathrm{wt} \% \mathrm{H}_{2} \mathrm{O}$ is $25 \%$ lower than the $K_{0}=272 \mathrm{GPa}$ reported for anhydrous $\left(\mathrm{Mg}_{0.6} \mathrm{Fe}_{0.4}\right)$-ppv (Mao et al., 2006). The reduction in $K_{0}(4.5 \%)$ and $G_{0}(8.1 \%)$ per wt. $\% \mathrm{H}_{2} \mathrm{O}$ for ppv upon hydration is about half that of ringwoodite, with about $7 \%$ reduction in $K_{0}$ and $15 \%$ reduction in $G_{0}$ per wt. $\% \mathrm{H}_{2} \mathrm{O}$ (Jacobsen et al., 2004). However, one of the most important results of the current calculations is that at pressures of $\mathrm{D}^{\prime \prime}$, the calculated reduction by 1 wt. $\% \mathrm{H}_{2} \mathrm{O}$ in ppv is only about $1 \%$ in $K$ and only about $3 \%$ in $G$, indicating that the hy-ppv structure is very stiff even in comparison with dry ppv. The combined influence of hydration, Al, and Fe-content in ppv remains to be explored in future work.

At $\mathrm{D}^{\prime \prime}$ conditions, the effects of hydration on the Hill average of the bulk and shear moduli can be compared with the influence of temperature by applying the temperature derivatives of the moduli for ppv reported by Stackhouse et al. (2005). At $120 \mathrm{GPa}$, the influence of $1 \mathrm{wt} \%$ 
$\mathrm{H}_{2} \mathrm{O}$ on the bulk modulus is equivalent to raising the temperature by about $300 \mathrm{~K}$, whereas the effect of 1 wt. $\% \mathrm{H}_{2} \mathrm{O}$ on the shear modulus is comparable to increasing temperature by about $675 \mathrm{~K}$. There is very little effect of hydration on the $V_{P} / V_{S}$ ratio of ppv, which shows about 0.01 increase $(\sim 0.5 \%)$ both at 0 and $120 \mathrm{GPa}$ for 1 wt. $\% \mathrm{H}_{2} \mathrm{O}$ (Table 2).

The single crystal elastic wave velocities were calculated using the Cristoffel equation:

$$
\operatorname{det}\left|c_{i j k l} n_{k} n_{l}-\rho V^{2} \delta_{i j}\right|=0
$$

where $c_{i j k l}$ is the elastic tensor, $n$ is the propagation direction, $\rho$ is the density, $V$ is the velocity and $\delta_{i j}$ is the Kronecker delta (Musgrave, 1970). The effect of $\mathrm{H}$ on the single crystal elastic wave velocities calculated from eqn. 4 at 0 and $120 \mathrm{GPa}$ are shown in Figure 6 . The full elastic tensor and density at 0 and $120 \mathrm{GPa}$ are listed in Table 2. At all pressures the presence of hydrogen reduces the elastic wave velocities for both $\mathrm{P}$ and $\mathrm{S}$ phases; however, the $\mathrm{S}$-wave velocities are more sensitive to hydration. At $120 \mathrm{GPa}$ the single crystal $V_{P}$ is generally unchanged by hydration while $V_{S}$ is reduced by $1.2 \%$ per wt. $\% \mathrm{H}_{2} \mathrm{O}$.

All ppv and hy-ppv structures were fit to $3^{\text {rd }}$-order Birch-Murnaghan equations of state (EOS), and EOS parameters are given in Table 3. At $0 \mathrm{GPa}$ the addition of 1.14 wt. $\% \mathrm{H}_{2} \mathrm{O}$ increases the molar volume of ppv by $0.5 \%$, and addition of $2.31 \mathrm{wt} . \% \mathrm{H}_{2} \mathrm{O}$ increases the molar volume by $0.9 \%$. For comparison, the $\mathrm{Mg}$ end-member hydrous ringwoodite containing $2.2 \mathrm{wt} . \%$ $\mathrm{H}_{2} \mathrm{O}$ studied by Inoue et al. (1998) had a molar volume $0.27 \%$ larger than dry Mg-ringwoodite (Weidner et al., 1984). Thus, at $0 \mathrm{GPa}$, the increase in molar volume due to hydration of ppv is about four times that of ringwoodite. However, due to the increased compressibility of the hy-ppv phase, at $120 \mathrm{GPa}$ the 1.14 wt. $\% \mathrm{H}_{2} \mathrm{O}$ hy-ppv structure has a molar volume that is $0.3 \%$ smaller than dry ppv, and the 2.31 wt. $\% \mathrm{H}_{2} \mathrm{O}$ hy-ppv structure has a molar volume that is $0.7 \%$ smaller than dry ppv.

Calculated vibrational density of states and infrared absorption spectra of hy-ppv are shown in Figure 7. Two O-H stretching bands are observed at 3492 and $3506 \mathrm{~cm}^{-1}$ at ambient pressure and correlate well with $\mathrm{OH}$ vibrational frequencies found in other high-pressure silicates (Libowitzky, 1999). With pressure these bands shift linearly with $\mathrm{d} v_{3492} / \mathrm{dP}=-2.25 \mathrm{~cm}^{-1} / \mathrm{GPa}$ and $\mathrm{d} v_{3506} / \mathrm{dP}=-1.94 \mathrm{~cm}^{-1} / \mathrm{GPa}$. In contrast to phase $\mathrm{D}$ we do not see hydrogen bond symmetrization in hy-ppv even at lower mantle pressures (Tsuchiya et al., 2005). The negative pressure shift of the $\mathrm{OH}$ modes is commonly observed in previous studies and occurs because the hydrogen 
bonds become more symmetric with increasing pressure which lengthens the $\mathrm{O}-\mathrm{H}$ bond, thereby reducing the frequency (Libowitzky, 1999). The lower-frequency mode corresponds to in-phase stretching of the two $\mathrm{OH}$ groups, and the higher-frequency mode corresponds to 180-degreeout-of-phase stretching between the two $\mathrm{OH}$ groups. Measurements of $\mathrm{OH}$ in minerals at lower mantle pressures using current techniques is challenging, but experimental observation of $\mathrm{OH}$ in ppv may be especially challenging because because ppv is not stable at low pressure (Mao et al., 2006), where many experimental measurements of $\mathrm{OH}$ in minerals are carried out.

\section{Summary}

Recent estimates of the return flux of water to the mantle via subduction suggest that perhaps several hundreds of ppm water may be retained in the slab beyond the depth of magma generation (Parai and Mukhopadhyay, 2012; Garth and Rietbrock, 2014). If slabs carry water through the lower mantle and into $\mathrm{D}^{\prime \prime}$, then ppv, the major silicate mineral in $\mathrm{D}^{\prime \prime}$, may be a potential host for water.

Primordial components, such as noble gases, in some ridge basalts may imply that magmas deriving from the deep mantle sample unmixed source regions (Craig et al., 1978; Gonnermann and Mukhopadhyay, 2007). The descent of slabs to the core mantle boundary (e.g. Garnero and McNamara, 2008) provides a mechanism of water incorporation into the $\mathrm{D}^{\prime \prime}$ region, through both nominally anhydrous minerals and potential stability of dense hydrous magnesium silicates such as phase $\mathrm{H}$ to lower mantle conditions (Nishi et al., 2014). Though the equilibrium assemblage of hydrous minerals under lower mantle conditions is not well known, and we therefore cannot comment on the most likely host for water in $\mathrm{D}^{\prime \prime}$, this study has shown for the first time that a stable structure of hy-ppv persists to $\mathrm{D}^{\prime \prime}$ pressures and displays modified elastic properties which may make it difficult to distinguish from brg from $V_{S}$ profiles alone.

The stability of a hy-ppv structure containing 1-2 wt. $\% \mathrm{H}_{2} \mathrm{O}$ at $\mathrm{D}^{\prime \prime}$ pressures implies that post-perovskite can potentially host a significant amount of recycled or primordial hydrogen near the Earth's core-mantle boundary. Future research requires determination of the hydrogen partition coefficient between post-perovskite and other lower mantle phases such as bridgmanite, especially with more realistic compositions that include iron and aluminum. Further constraints on the effects of hydration on the mechanical and elastic properties of post-perovskite, especially at high temperature, will be important for future work that may provide insight into the fate of 
water in the seismically heterogeneous core-mantle boundary region.

\section{Acknowledgements}

JPT was supported by the EAPSI Program of the U.S. National Science Foundation (NSF) grant number 1209633 and the Japan Society for the Promotion of Science, and by the Premier Research Institute for Ultrahigh-pressure Sciences (PRIUS) joint research program carried out at the Geodynamics Research Center, Ehime University. This research was supported by NSF grants EAR-1452344 (SDJ), EAR-0847951 (CRB), the Carnegie/DOE Alliance Center (CDAC), the David and Lucile Packard Foundation, and by the Alexander Von Humboldt Foundation.

\section{References}

Baroni, S., de Gironcoli, S., Dal Corso, A., 2001. Phonons and related crystal properties from density-functional perturbation theory. Reviews of Modern Physics 73, 515-562.

Blanchard, M., Balan, E., Wright, K., 2009. Incorporation of water in iron-free ringwoodite: A first-principles study. American Mineralogist 94, 83-89.

Bolfan-Casanova, N., Keppler, H., Rubie, D. C., 2000. Water partitioning between nominally anhydrous minerals in the $\mathrm{MgO}-\mathrm{SiO}_{2}-\mathrm{H}_{2} \mathrm{O}$ system up to $24 \mathrm{GPa}$ : Implications for the distribution of water in the Earths mantle. Earth and Planetary Science Letters 182, 209-221.

Bolfan-Casanova, N., Keppler, H., Rubie, D. C., 2003. Water partitioning at $660 \mathrm{~km}$ depth and evidence for very low water solubility in magnesium silicate perovskite. Geophysical Research Letters 30, 1905.

Born, M., Huang, K., 1954. Dynamical Theory of Crystal Lattices. Oxford University Press, London, U.K.

Brodholt, J. P., Refson, K., 2000. An ab initio study of hydrogen in forsterite and a possible mechanism for hydrolytic weakening. Journal of Geophysical Research 105, 18977-18982.

Craig, H., Lupton, J. E., Welhan, J. A., Poreda, R., 1978. Helium isotope ratios in yellowstone and lassen park volcanic gases. Geophysical Research Letters 5, 897-900.

Ferot, A., Bolfan-Casanova, N., 2012. Water storage capacity in olivine and pyroxene to 14 GPa: Implications for the water content of the Earth's upper mantle and nature of seismic discontinuities. Earth and Planetary Science Letters $349-350,218-230$.

Ganskow, G., Boffa-Ballaran, T., Langenhorst, F., 2010. Effect of iron on the compressibility of hydrous ringwoodite. American Mineralogist 95, 747-753.

Garnero, E. J., McNamara, A. K., 2008. Structure and dynamics of Earth's lower mantle. Science 320, 626-628.

Garth, T., Rietbrock, A., 2014. Order of magnitude increase in subducted $\mathrm{H}_{2} \mathrm{O}$ due to hydrated normal faults within the Wadati-Benioff zone. Geology 42, 207-210.

Giannozzi, P., et al., 2009. QUANTUM ESPRESSO: a modular and open-source software project for quantum simulations of materials. Journal of Physics: Condensed Matter 21, 395502. 
Gibbs, G. V., Cox, D. F., Boisen Jr., M. B., Downs, R. T., Ross, N. L., 2003. The electron localization function: a tool for locating favorable proton docking sites in the silica polymorphs. Physics and Chemistry of Minerals 30, $305-316$.

Gonnermann, H. M., Mukhopadhyay, S., 2007. Non-equilibrium degassing and a primordial source for helium in oceanisland volcanism. Nature 449, 1037-1040.

Grocholski, B., Catalli, K., Shim, S.-H., Prakapenka, V., 2012. Mineralogical effects on the detectability of the postperovskite boundary. Proceedings of the National Academy of Sciences 109, 2275-2279.

Hernandez, E. R., Alfe, D., Brodholt, J., 2013. The incorporation of water into lower-mantle perovskites: A firstprinciples study. Earth and Planetary Science Letters 364, 37-43.

Hill, R., 1952. The elastic behavior of a crystalline aggregate. Proceedings of the Physical Society A 65, 349-354.

Hohenberg, P., 1964. Inhomogeneous electron gas. Physical Review 136, B864-B871.

Inoue, T., Wada, T., Sasaki, R., Yurimoto, H., 2010. Water partitioning in the Earths mantle. Physics of the Earth and Planetary Interiors 183, 245-251.

Inoue, T., Weidner, D., Northrup, P., Parise, J., 1998. Elastic properties of hydrous ringwoodite $\left(\gamma\right.$-phase) in $\mathrm{Mg}_{2} \mathrm{SiO}_{4}$. Earth and Planetary Science Letters 160, 107-113.

Jacobsen, S. D., Smyth, J. R., Spetzler, H., Holl, C. M., Frost, D. J., 2004. Sound velocities and elastic constants of iron-bearing hydrous ringwoodite. Physics of the Earth and Planetary Interiors 143-144, 47-56.

Karki, B. B., Stixrude, L., Wentzcovitch, R. M., 2001. High-pressure elastic properties of major materials of earth's mantle from first principles. Reviews of Geophysics 39, 507-534.

Karki, B. B., Wentzcovitch, R. M., 2000. Ab initio lattice dynamics of $\mathrm{MgSiO}_{3}$ perovskite at high pressure. Physical Review B 62, 750-756

Kohlstedt, D., Keppler, H., Rubie, D., 1996. Solubility of water in the $\alpha, \beta$ and $\gamma$ phases of $(\mathrm{Mg}, \mathrm{Fe})_{2} \mathrm{SiO}_{4}$. Contributions to Mineralogy and Petrology 123, 345-357.

Kohn, W., Sham, L. J., 1965. Self-consistent equations including exchange and correlation effects. Physical Review 140 , A1133-A1138.

Kudoh, Y., Inoue, T., 1999. Mg-vacant structural modules and dilution of the symmetry of hydrous wadsleyite, $\beta$ $\mathrm{Mg}_{2-x} \mathrm{SiH}_{2 x} \mathrm{O}_{4}$ with $0.00 \leq \mathrm{x} \leq 0.25$. Physics and Chemistry of Minerals 26, 382-388.

Li, L., Brodholt, J., Alfe, D., 2009. Structure and elasticity of hydrous ringwoodite: A first principle investigation. Physics of the Earth and Planetary Interiors 177, 103-115.

Libowitzky, E., 1999. Correlation of O-H stretching frequencies and O-H...O hydrogen bond lengths in minerals. Monatschefte fr Chemie 130, 1047-1059.

Litasov, K., Ohtani, E., Langenhorst, F., Yurimoto, H., Kubo, T., Konda, T., 2003. Water solubility in Mg-perovskites and water storage capacity in the lower mantle. Earth and Planetary Science Letters 211, 189-203.

Mao, W. L., Mao, H.-k., Prakapenka, V. B., Shu, J., Hemley, R. J., 2006. The effect of pressure on the structure and volume of ferromagnesian post-perovskite. Geophysical Research Letters 33, L12S02.

Monkhorst, H. J., Pack, J. D., 1976. Special points for Brillouin-zone integrations. Physical Review B 13, 5188-5192.

Murakami, M., Hirose, K., 2005. Post-perovskite phase transition and mineral chemistry in the pyrolitic lowermost mantle. Geophysical Research Letters 32, L03304.

Murakami, M., Hirose, K., Kawamura, K., Sata, N., Ohishi, Y., 2004. Post-perovskite phase transition in $\mathrm{MgSiO}_{3}$. Science 304, 855-858. 
Murakami, M., Hirose, K., Yurimoto, H., Nakashima, S., Takafuji, N., 2002. Water in Earth’s lower mantle. Science 295, $1885-1887$.

Musgrave, M. J. P., 1970. Crystal Acoustics. Holden-Day, Boca Raton, FL, USA.

Nishi, M., Irifune, T., Tsuchiya, J., Tange, Y., Nishihara, Y., K., F., Higo, Y., 2014. Stability of hydrous silicate at high pressures and water transport to the deep lower mantle. Nature Geoscience 7, 224-227.

Nomura, R., Hirose, K., Uesugi, K., Ohishi, Y., Tsuchiyama, A., Miyake, A., Ueno, Y., 2014. Temperature inferred from the solidus of pyrolite. Science 343, 522-525.

Nowacki, A., Wookey, J., Kendall, J.-M., 2010. Deformation of the lowermost mantle from seismic anisotropy. Nature 467, 1091-1096.

Oganov, A. R., Ono, S., 2004. Theoretical and experimental evidence for a post-perovskite phase of $\mathrm{MgSiO}_{3}$ in earth's d" layer. Nature 430, 445-448.

Parai, R., Mukhopadhyay, S., 2012. How large is the subducted water flux? New constraints on mantle regassing rates. Earth and Planetary Science Letters 317-318, 396-406.

Pearson, D. G., Brenker, F. E., Nestola, F., McNeill, J., Nasdala, L., Hutchison, M. T., Matveev, S., Mather, K., Silversmit, G., Schmitz, S., Vekemans, B., Vincze, L., 2014. Hydrous mantle transition zone indicated by ringwoodite included within diamond. Nature 507, 221-224.

Perdew, J. P., Burke, K., Wang, Y., 1996. Generalized gradient approximation for the exchange-correlation hole of a many-electron system. Physical Review B 54, 16533-16539.

Schmandt, B., Jacobsen, S. D., Becker, T. W., Liu, Z., Ducker, K. G., 2014. Dehydration melting at the top of the lower mantle. Science 344, 1265-1268.

Stackhouse, S., Brodholt, J., Wookey, J., Kendall, J.-M., Price, G., 2005. The effect of temperature on the seismic anisotropy of the perovskite and post-perovskite polymorphs of $\mathrm{MgSiO}_{3}$. Earth and Planetary Science Letters 230, $1-10$.

Tenner, T. J., Hirschmann, M. M., Withers, A. C., Ardia, P., 2012. $\mathrm{H}_{2} \mathrm{O}$ storage capacity of olivine and low-Ca pyroxene from 10 to $13 \mathrm{GPa}$ : Consequences for dehydration melting above the transition zone. Contributions to Mineralogy and Petrology 163, 297-316.

Troullier, N., Martins, J. L., 1991. Efficient pseudopotentials for plane-wave calculations. Physical Review B 43, 19932006.

Tsuchiya, J., Tsuchiya, T., 2009. First principles investigation of the structural and elastic properties of hydrous wadsleyite under pressure. Journal of Geophysical Research 114, B02206.

Tsuchiya, J., Tsuchiya, T., Tsuneyuki, S., 2005. First-principles study of hydrogen bond symmetrization of phase D under high pressure. American Mineralogist 90, 44-49.

Tsuchiya, T., Tsuchiya, J., Umemoto, K., Wentzcovitch, R. M., 2004. Phase transition in $\mathrm{MgSiO}_{3}$ perovskite in the earth's lower mantle. Earth and Planetary Science Letters 224, 241-248.

Umemoto, K., Wentzcovitch, R., Hirschmann, M. M., Kohlstedt, D. L., Withers, A. S., 2011. A first-principles investigation of hydrous defects and IR frequencies in forsterite: The case for Si vacancies. American Mineralogist 96, $1475-1479$.

Verma, A. K., Karki, B. B., 2009. Ab initio investigations of native and protonic point defects in $\mathrm{Mg}_{2} \mathrm{SiO}_{4}$ polymorphs under high pressure. Earth and Planetary Science Letters 285, 140-149. 
324 Weidner, D., Sawamoto, H., Sasaki, S., Kumazawa, M., 1984. Elasticity of $\mathrm{Mg}_{2} \mathrm{SiO}_{4}$ spinel. Journal of Geophysical $325 \quad$ Research 89, 7852-7860.

326 Williams, Q., Hemley, R. J., 2001. Hydrogen in the deep Earth. Annual Review of Earth and Planetary Sciences 29, $327 \quad 365-418$.

328 Wookey, J., Stackhouse, S., Kendall, J.-M., Brodholt, J., Price, G. D., 2005. Efficacy of the post-perovskite phase as an 329 explanation for lowermost mantle seismic properties. Nature 438, 1004-1007.

330 Zhang, L., Meng, Y., Dera, P., Yang, W., Mao, W. L., Mao, H.-k., 2013. Single-crystal structure determination of $331 \quad(\mathrm{Mg}, \mathrm{Fe}) \mathrm{SiO}_{3}$ postperovskite. Proceedings of the National Academy of Sciences 110, 6292-6295. 

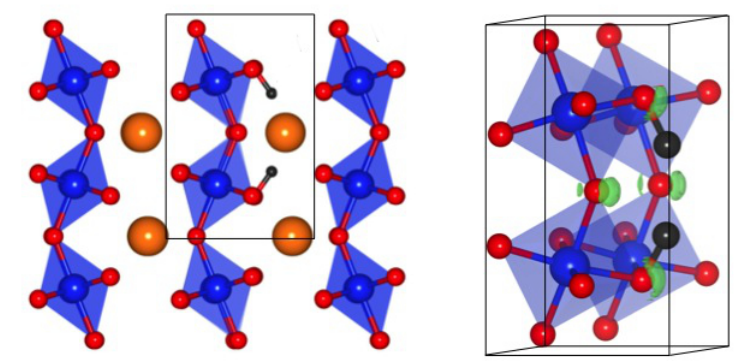

Figure 1: Predicted stable hydrogen defect structure of hy-ppv at $120 \mathrm{GPa}$. Left: view of hy-ppv down the $a$-axis. Right: electron localization function 93-percentile iso-surface (green) of a $\mathrm{Mg}$ vacancy site in hy-ppv with super-imposed hydrogen groups. Atom positions are shown as oxygen (red), silicon (blue), magnesium (orange), and hydrogen (black). Lattice parameters and hydrogen-bond distances of the structure at 0 and $120 \mathrm{GPa}$ are listed in Table 1. Fractional coordinates of atom positions for all structures are provided in the supplementary materials. 

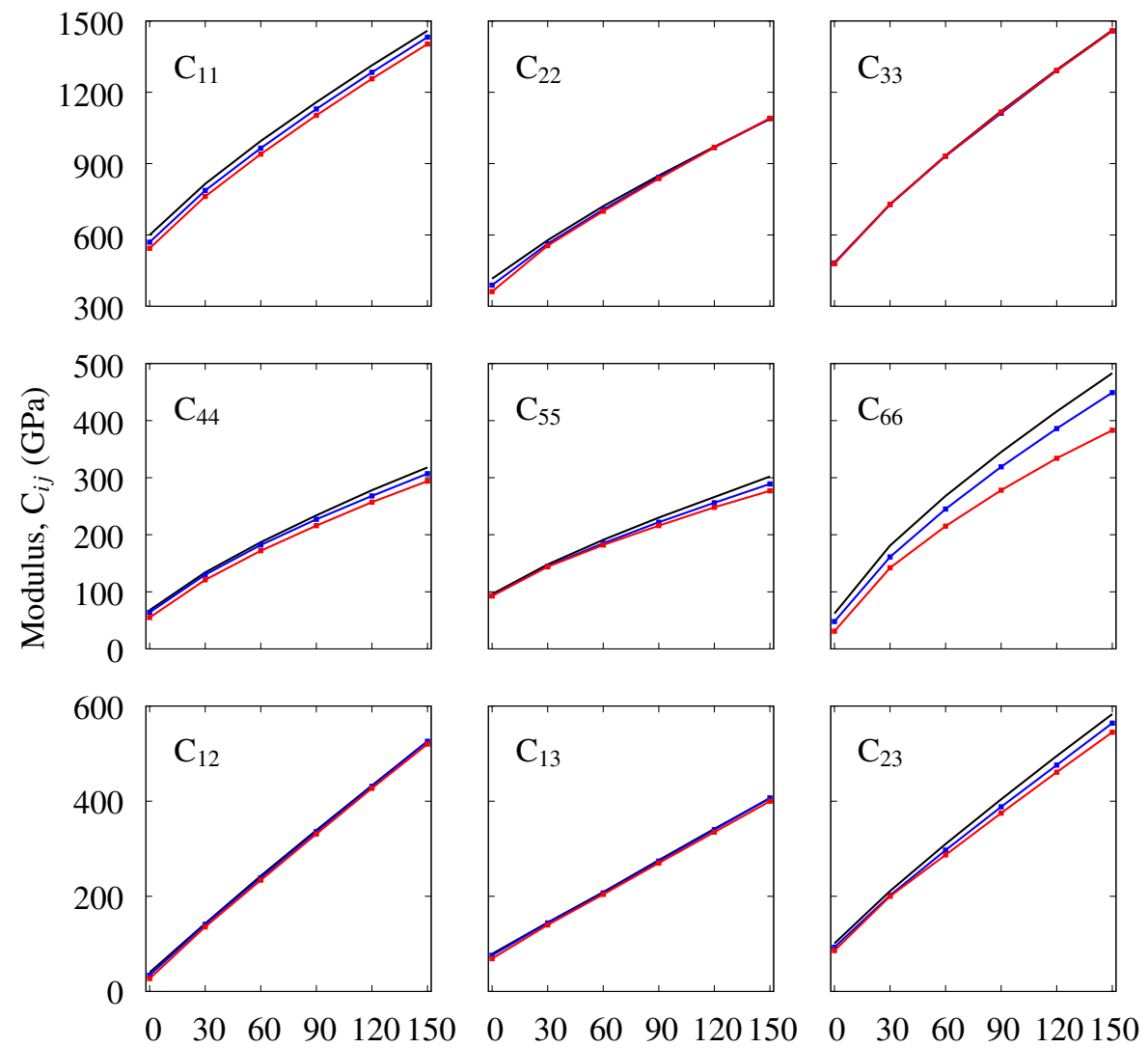

Pressure, $P(\mathrm{GPa})$

Figure 2: Elastic tensor components (using Voigt notation) of ppv (black) and hy-ppv (1.14 wt.\% $\mathrm{H}_{2} \mathrm{O}$ in blue, $2.31 \mathrm{wt} . \%$ $\mathrm{H}_{2} \mathrm{O}$ in red). $\mathrm{C}_{22}, \mathrm{C}_{33}, \mathrm{C}_{12}$, and $\mathrm{C}_{13}$ are relatively insensitive to hydration at $\mathrm{D}^{\prime \prime}$ pressures, while $\mathrm{C}_{11}, \mathrm{C}_{44}, \mathrm{C}_{55}, \mathrm{C}_{66}$, and $\mathrm{C}_{23}$ are more sensitive to hydration. At $120 \mathrm{GPa}_{22}$ and $\mathrm{C}_{33}$ are reduced by approximately $0.1 \%$ while $\mathrm{C}_{66}$ is reduced by approximately $20 \%$ with addition of $2.31 \mathrm{wt} . \% \mathrm{H}_{2} \mathrm{O}$. 


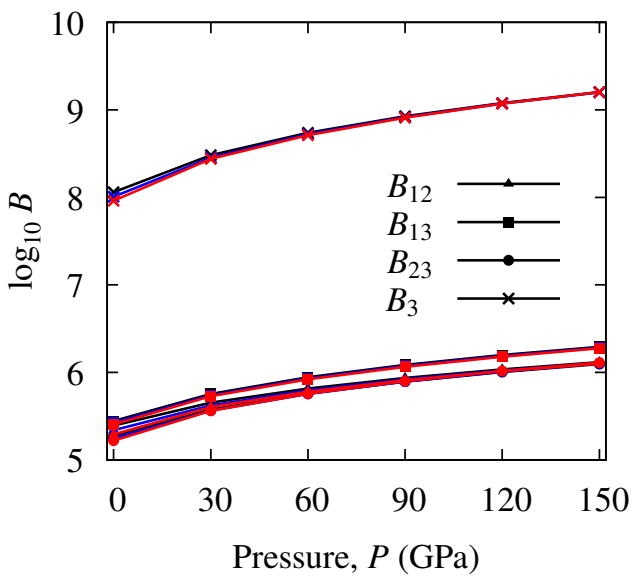

Figure 3: Born stability criteria for ppv (black), and hy-ppv (1.14 wt. $\% \mathrm{H}_{2} \mathrm{O}$ in blue and 2.31 wt. $\% \mathrm{H}_{2} \mathrm{O}$ in red). Mechanical stability of the lattice requires each quantity be greater than zero. Addition of hydrogen to the ppv lattice does not destabilize the ppv structure. 


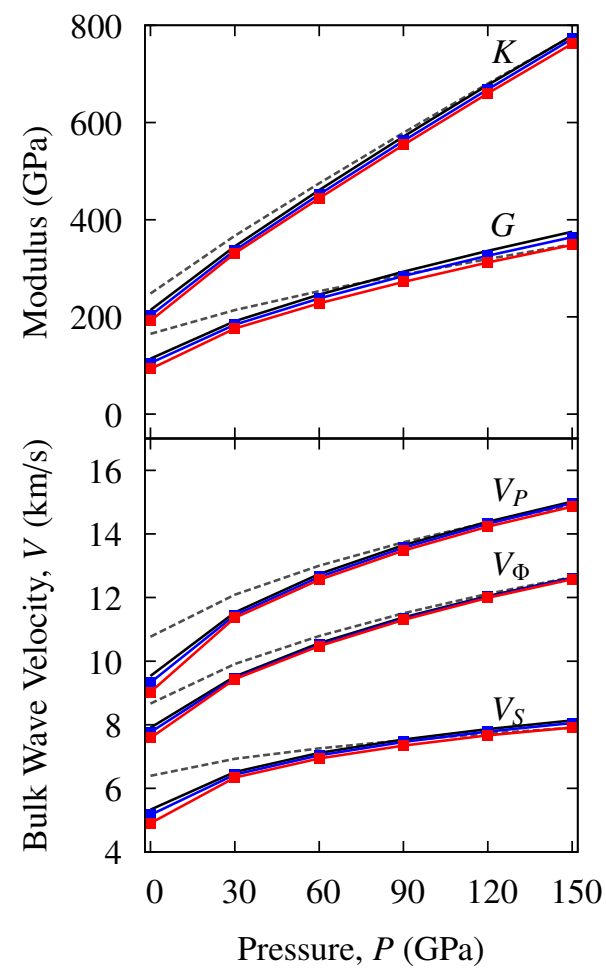

Figure 4: Bulk elastic properties of brg (dashed), ppv (black), and hy-ppv (1.14 wt. $\% \mathrm{H}_{2} \mathrm{O}$ in blue, 2.31 wt. $\% \mathrm{H}_{2} \mathrm{O}$ in red). Voigt-Reuss-Hill averaged bulk modulus and shear modulus (top), and bulk wave velocities (bottom). Bulk sound velocity is relatively insensitive to hydrogen content, while bulk shear velocity is most sensitive. 


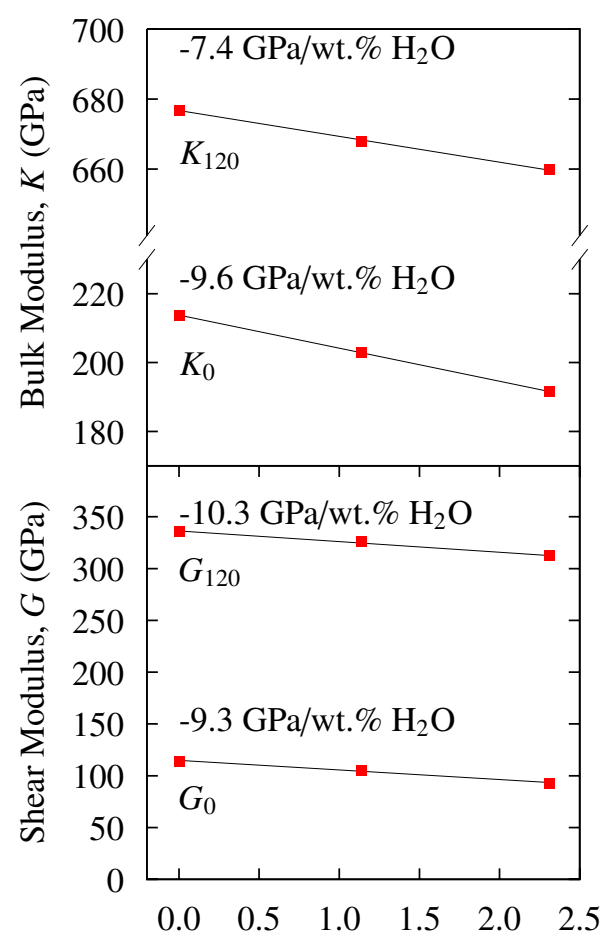

Water Content (wt.\% $\mathrm{H}_{2} \mathrm{O}$ )

Figure 5: Top: Dependence of bulk modulus (top) and shear modulus (bottom), upon water content for ppv at 0 and 120 GPa. 


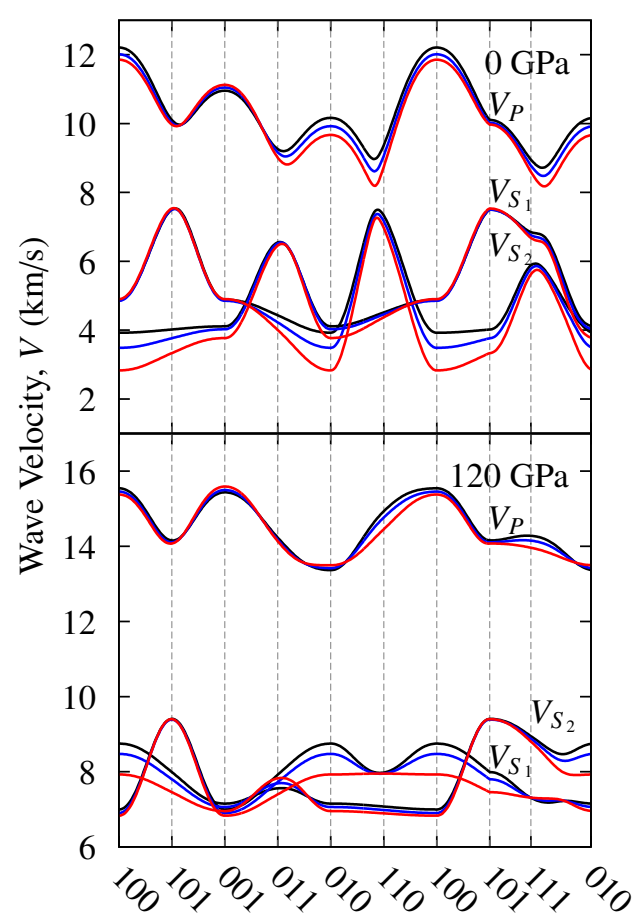

Propagation Direction, [hkl]

Figure 6: Single crystal elastic wave velocities calculated for dry ppv (black), 1.14 wt.\% $\mathrm{H}_{2} \mathrm{O}$ (blue), and 2.31 wt.\% $\mathrm{H}_{2} \mathrm{O}$ (red). The presence of hydrogen has a pronounced effect on S-wave velocities relative to P-wave velocities. The presence of hydrogen does not noticeably change the minimum or maximum velocity directions. 


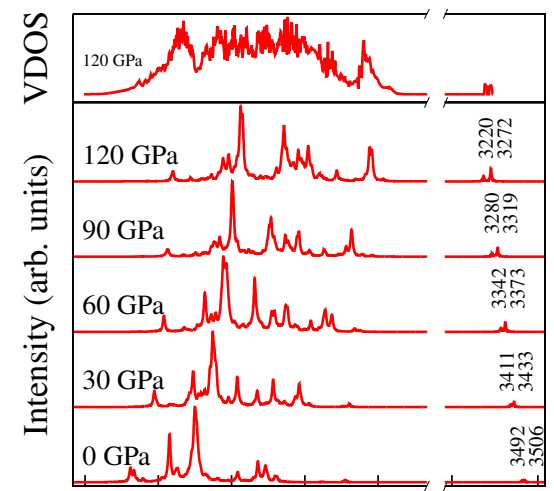

$0 \quad 300600900120030003600$

Wavenumber, $v\left(\mathrm{~cm}^{-1}\right)$

Figure 7: Top: Vibrational density of states for hy-ppv $\left(1.14 \mathrm{wt} . \% \mathrm{H}_{2} \mathrm{O}\right)$ at $120 \mathrm{GPa}$. Bottom: Calculated IR absorption spectra of hy-ppv at mantle pressures. Low-wavenumber peaks are lattice modes, and the two high-wavenumber peaks are characteristic of $\mathrm{OH}$, representing in-phase stretching (low) and out-of-phase stretching (high). 


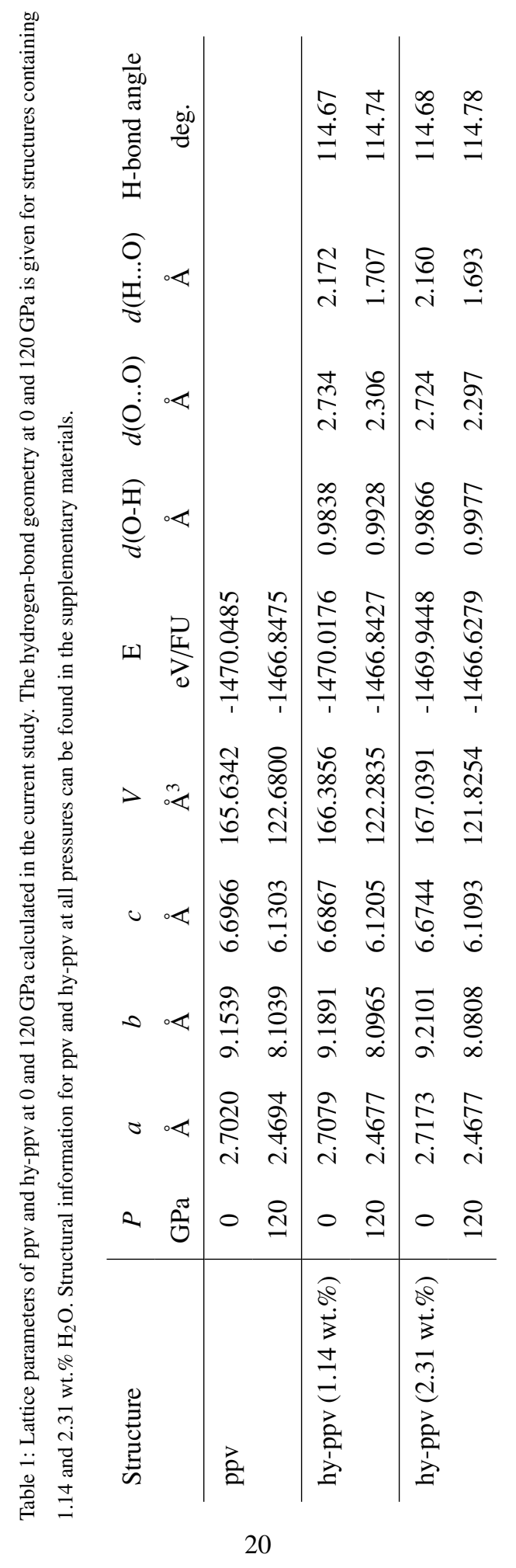




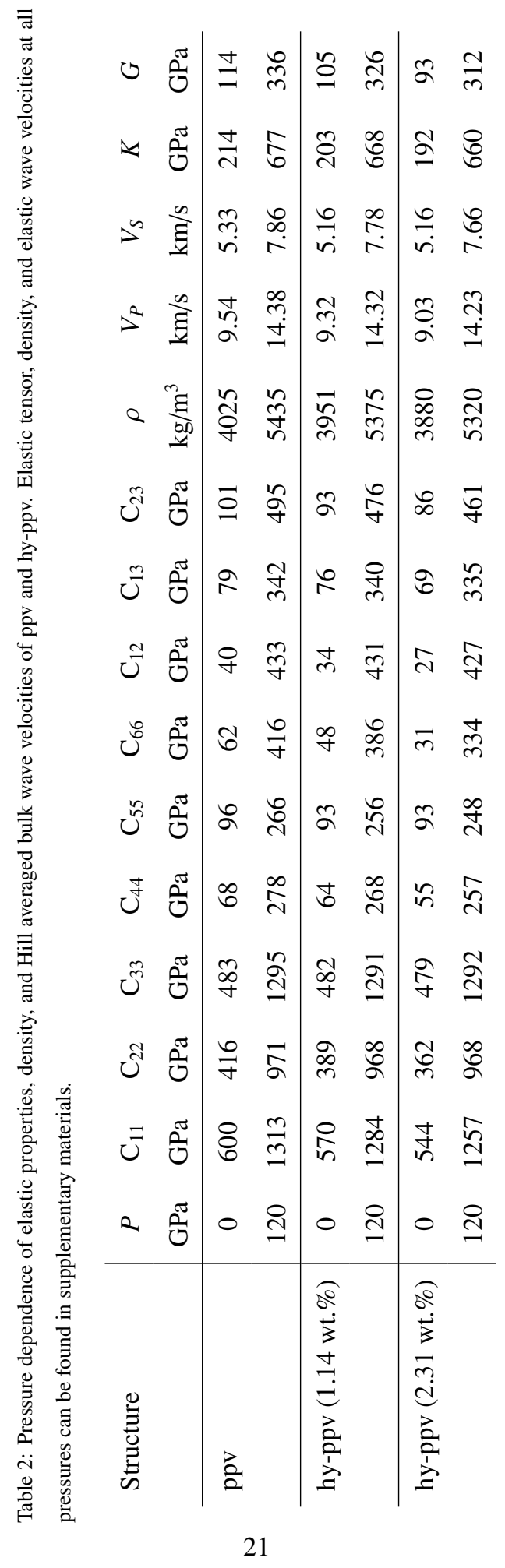


Table 3: Equation-of-state parameters of post-perovskite with varying hydrogen content. Bulk modulus $\left(K_{T 0}\right)$ and its pressure derivative $\left(K_{T 0}^{\prime}\right)$ were fit using a 3rd-order Birch-Murnaghan equation of state.

\begin{tabular}{l|ccc} 
Structure & $K_{T 0}$ & $K_{T 0}^{\prime}$ & $\begin{array}{c}V_{T 0} \\
\text { GPa }\end{array}$ \\
& 210 & 4.27 & 24.94 \\
\hline ppv & 201 & 4.28 & 25.05 \\
hy-ppv (1.14 wt.\% $\left.\mathrm{H}_{2} \mathrm{O}\right)$ & 191 & 4.32 & 25.15 \\
hy-ppv (2.31 wt.\% $\left.\mathrm{H}_{2} \mathrm{O}\right)$ & 15
\end{tabular}

